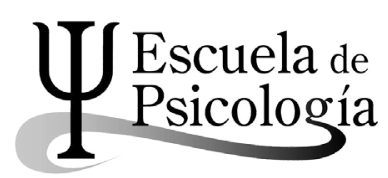

Wímb lu, Rev. electrónica de estudiantes Esc. de psicología, Univ. de Costa Rica. 10 (1): 57-66, 2015 / ISSN: $1659-2107$

\title{
LA IMPORTANCIA DE INCLUIR LAS COMPETENCIAS INTERCULTURALES EN LAS RELACIONES CON POBLACION REFUGIADA
}

The importance of including intercultural competences in dealing with refugees

Sebastián May Grosser*

Resumen: Este ensayo presenta la importancia de incorporar el desarrollo de competencias interculturales en el trabajo con población refugiada, reflexionado sobre el potencial que esto tiene tanto para la población refugiada, como para la población costarricense como país receptor.

Palabras claves: Psicología Comunitaria, Migración, Refugio, Competencias Interculturales.

Abstract: This essay discusses the concepts of intercultural competence and the potential of including this perspective in the work with refugees, reflecting on the impact this could bring to the refugee population and for the costarricans.

Key Words: Community Psychology, Migration, Refuge, Intercultural Competence.

Estudiante de psicología, Universidad de Costa Rica.

Correo electrónico: maysebastian@hotmail.com.

Recepción: 29/8/2013 Aceptación: 9/12/2014 
El 20 de Junio de cada año se conmemora el Día Mundial del Refugiado, promovido por el Alto Comisionado de las Naciones Unidas para los Refugiados (ACNUR), y en Costa Rica a lo largo de los años, se han realizado campañas de concientización sobre la temática, por ejemplo en el 2013 que se pegaron a lo largo de San José una serie de 140 retratos de miembros de siete familias refugiadas (Alto Comisionado de las Naciones Unidas para los Refugiados [ACNUR], 2013), mientras que en el 2014 en ese día se realizó un reconocimiento a 36 empresas que han facilitado la incorporación de personas refugiadas a sus negocios (ACNUR, 2014), estas y otras campañas que se han hecho, como la de figuras históricas que fueron refugiados en algún momento de sus vidas, buscan concientizar a la población general de las realidades humanas que están detrás de esta temática y los derechos de quienes se ven en la necesidad de abandonar sus países y buscar refugio en otras latitudes.

Las personas refugiadas, según la Convención de 1951 sobre el Estatuto de los Refugiados (ACNUR, 1951), es aquella persona quien:

(...) debido a fundados temores de ser perseguida por motivos de raza, religión, nacionalidad, pertenencia a determinado grupo social u opiniones políticas, se encuentre fuera del país de su nacionalidad y no pueda o, a causa de dichos temores, no quiera acogerse a la protección de tal país; o que, careciendo de nacionalidad y hallándose, a consecuencia de tales acontecimientos, fuera del país donde antes tuviera su residencia habitual, no pueda o, a causa de dichos temores, no quiera regresar a él (ACNUR, 1951, p. 1).

Si bien, las épocas de los grandes campos de refugiados que existieron en Costa Rica en la década de los 80's y 90's por los conflictos armados centroamericanos han quedado en el pasado, Costa Rica sigue siendo un país que hospeda un gran número de personas refugiadas, siendo que desde el año 2000, 12.700 personas de 43 nacionalidades han sido reconocidas como refugiadas y aproximadamente se reciben anualmente 1100 nuevas solicitudes de refugio, actualmente la gran mayoría de esta población es de origen colombiano (90\%), siendo Costa Rica el segundo país que más personas de dicho país recibe en condición de refugio (ACNUR, 2013). Esto ha hecho que el tema haya sido estudiado ampliamente en diversos espacios, como ejemplos recientes se puede mencionar la investigación realizada por Dobles, Vargas y Amador (2014) sobre la experiencia nicaragüense y colombiana en Costa Rica y políticas públicas, así como para poner un ejemplo, se pueden encontrar trabajos finales de graduación realizados en la Universidad de Costa Rica en última década sobre el tema de personas refugiadas colombianas en Costa Rica, los cuales abordan la temática desde las diversas áreas de las ciencias sociales como son la psicología (Morales Morera y Vargas Selva, 2008; Duque Echeverri, 2009; Ugalde Watson, 2009;), la antropología (Salas Matamoros, 2014), el derecho (Gonzáles Villalobos y Hernández Vindas, 2005; Medina 
Amador, 2006; Duneque, 2011), el trabajo social (Chávez Soto, 2006) y las ciencias políticas (Gutiérrez Bonilla y Valverde López, 2011) ${ }^{1}$.

A pesar de esto, el tema de los refugiados en Costa Rica y los derechos de la población refugiada, sigue siendo un tema de desconocimiento por parte de la población general, y genera muchas veces rechazo de parte de los costarricenses, por ejemplo hacia los migrantes colombianos, como señalan en las conclusiones de su investigación Morales Morera y Vargas Selva (2008), quienes trabajaron historias de vida:

Se establecen vínculos sociales superficiales, "para quedar bien"; donde no se establecen compromisos e impera el temor y la xenofobia. Esto es empeorado por la actitud y acciones de figuras políticas del país y de los medios de comunicación que transmiten una visión negativa, alarmista y generalizada sobre los y las colombianos (as) (p.208).

Actualmente, la política de ACNUR es trabajar bajo una estrategia local de integración, destinada principalmente a refugiados colombianos la cual es desarrollada en coordinación con instituciones gubernamentales, académicas y ONG's. Este programa de integración local busca:

Propiciar la integración de las personas refugiadas en la sociedad costarricense a través de seguimiento psicosocial y de iniciativas como los hogares comunitarios para el cuido de niñas y niños pequeños, las capacitaciones en áreas técnicas como computación y la organización de grupos de personas refugiadas que promuevan su participación en la comunidad nacional, entre otros proyectos. (ACNUR, 2011, p.1)

El trabajo que se realiza con la integración de la población incluye otra serie de proyectos que buscan empoderar a las personas, y que en teoría, parte de un enfoque de trabajo comunitario que permita a "las comunidades trabajar para prevenir los problemas sociales y a enfrentar directamente aquellos que se presentan, en vez de necesitar que agentes externos intervengan y asuman estas responsabilidades" (ACNUR 2008, p.10), sin embargo, considero que no se le da la relevancia a un aspecto fundamental, como es el promover y fomentar competencias interculturales tanto en las personas refugiadas, como en aquellas comunidades donde estos llegan. Se debe entender aquí, que cuando hablamos de cultura nos referimos a todo el conjunto de sistemas de valores, creencias, tradiciones y formas de interactuar de un determinado grupo (UNESCO, 2013), por lo que las interacciones interculturales se darán cuando grupos o individuos se encuentren.

En un primer momento, para el abordaje del presente ensayo, es necesario definir el término competencias interculturales, para poder empezar a comprender su relevancia en el marco de las múltiples interacciones entre diferentes grupos culturales, de las cuales las situaciones de refugio, son solo uno de los variados escenarios donde se presentan. 
La Organización de las Naciones Unidas para la Educación, la Ciencia y la Cultura, (United Nations Educational, Scientific and Cultural Organization [UNESCO], 2013), define las competencias interculturales como:

Tener los conocimientos pertinentes suficientes sobre las culturas particulares, así como el conocimiento general sobre los tipos de problemas que surgen cuando los miembros de las diferentes culturas interactúan, manteniendo actitudes receptivas que fomenten el establecimiento y mantenimiento de contactos con diversos otros, además de contar con las habilidades necesarias de aprovechar los conocimientos y las actitudes en la interacción con otras personas de diferentes culturas (p.16).

Estas competencias permiten valorar a los otros, entender nuestra propia visión de mundo, ver las similitudes y diferencias en las perspectivas de los otros, mantener un verdadero diálogo intercultural ${ }^{2}$, poder cambiar temporalmente nuestra perspectiva, construir vínculos personales transculturales y alcanzar una humildad cultural que combine el respeto con la autoconciencia (UNESCO, 2013).

Las competencias interculturales permiten empoderar a los grupos y personas participantes y les facilitan interactuar con los "otros" culturales con el fin de salvar las diferencias, desactivar conflictos y establecer las bases de una convivencia, facilitando de esta manera, las relaciones e interacciones entre personas de diferentes orígenes y culturas, así como dentro de grupos heterogéneos, todos los cuales deben aprender a vivir juntos en paz.

Siendo que, en el mundo globalizado en que vivimos, todo el mundo tendrá en algún momento la necesidad de poseer en cierta medida competencias interculturales, deben por lo tanto realizarse todos los esfuerzos para asegurar que todos ellos puedan adquirirlas (UNESCO 2013).

Así, las competencias interculturales parten de, y se complementan con, las perspectivas de Derechos Humanos como ejes transversales necesarios para la consecución de sociedades más justas e igualitarias con todos sus miembros sin ningún tipo de distinción. Estas competencias, se vuelven necesarias cuando nos enfrentamos a situaciones en las cuales nos encontramos con grupos culturales (o miembros de grupos culturales) que son diferentes al nuestro. En el caso de encuentros de larga duración (como el que se da en las situaciones de refugio), la ausencia de estas competencias suele llevar a reacciones que van desde el aislamiento, hasta la negación de los valores propios como medio para acelerar la "adaptación" al nuevo contexto.

Estos problemas se presentan, no solo por las características de las personas que viajan y las competencias que estos posean, sino también en la mayoría de los casos, por la forma en que las comunidades entienden la adaptación, que muchas veces se contrapone a una verdadera integración, la diferencia de estos dos conceptos, aunque pueda parecer semántica, en realidad es mucho más profunda, y se relaciona con la forma en que miramos a ese otro que llega. Es importante señalar, que en este ensayo se habla de integración, entendiendo este concepto 
como la posibilidad de que grupos de culturas distintas convivan bajo un marco de mutuo respeto por las diferencias, posibilitando esto que ambas partes puedan, y estén dispuestas a, aprender del otro grupo sin que el bagaje cultural de un grupo se imponga sobre el otro. Esto va claramente más allá de la versión más tradicional de integración que suele trabajarse desde distintas organizaciones internacionales y nacionales, donde lo que predomina es una "integración" al mercado laboral y medios de producción. Si bien satisfacer las necesidades económicas es básico para la satisfacción de las necesidades superiores de las personas, acá al hablar de integración se está haciendo referencia a aquellas cosas más intangibles de la cultura de cada grupo, que se ponen en juego en los encuentros entre culturas.

En los casos en los que se busca la adaptación, el concepto que está detrás es el de que aquellas personas que llegan deben acomodarse o amoldarse (en la mayoría de los casos de la forma más rápida posible) a las características culturales de la comunidad a la cual llegan, aun cuando esto implique la pérdida o negación de las cultura de origen. Dobles y Jiménez (en: ACNUR, 2008a) señalan que en el caso de los encuentros entre culturas, el fenómeno que se ha presentado mayoritariamente ha sido que tanto el grupo que llega como el grupo hegemónico que recibe, buscan eliminar los conflictos que puedan surgir por diferencias culturales, eliminando el bagaje cultural que traen las personas que llegan y exigiéndoles que se "acomoden" a la sociedad receptora como medio para facilitar esta "adaptación". Mientras que por otro lado la integración, implica la incorporación de aquellos "otros" ajenos al grupo mayoritario, sin que sea necesario para esto, que aquellos rasgos culturales diferentes sean eliminados o dominados por los rasgos de la mayoría.

Un ejemplo de esto se puede ver en el estudio de Smith (2008) de una comunidad donde el asentamiento de refugiados se realizaba de manera exitosa (1 de cada 6 personas de la comunidad era un refugiado), se encontraron tres factores que tenían los miembros de la comunidad que facilitaban la inserción de las personas refugiadas, los cuales los autores los relacionaron con aspectos "ecológicos" de la comunidad (historia, necesidades económicas y estructura de la organización que ayudaba a recibir a los refugiados).

Sin embargo, es de subrayar que el trabajo incorpora el concepto de inserción a través de la adaptación, lo que en el estudio queda incorporado en la concepción de la que parte al definir que: el asentamiento de los refugiados de forma exitosa se alcanza cuando estos logran adaptarse a la cultura nativa, un ejemplo de esto lo podemos encontrar en una de las conclusiones donde se señala: "Las poblaciones actuales de migrantes que vienen de Asia y África (Birmano, Bantusomali y Sudanés) experimentan retos más profundos para adaptarse a la cultura americana que los refugiados europeos (Bosnios y Rusos) tuvieron en los 1990 's" (Smith, 2008, p. 339) ${ }^{3}$. 
De la misma manera, podemos observar rasgos de esta concepción de adaptación a la cultura dominante, en el trabajo de Morales Morera y Vargas Selva (2008), con refugiados colombianos en Costa Rica, que en una de sus conclusiones nos mencionan:

A través de los relatos de las y los entrevistados (as) se percibe por parte de los hijos e hijas, el rechazo de las características de la identidad colombiana (en los casos de Omar y Nerea) y un deseo profundo de integración a la costarricense. La nacionalidad colombiana es percibida como una barrera para avanzar en Costa Rica y el resto del mundo (p.201).

En los dos casos, podemos observar cómo la practica dominante es la de buscar procesos de adaptación y no de integración. Ahora, es en este punto donde el trabajo de competencias interculturales toma importancia, ya que es a través de estas que se podría lograr crear en las personas esas capacidades de tolerancia, y más importante aún de aprender de las propias características culturales, a través de la interacción con personas de otras culturas, aspecto que se pierde cuando lo que se busca es que, quien ingresa a la comunidad deje afuera aquellos aspectos culturales que difieran, siempre y cuando estas no incluyan prácticas que violenten los derechos humanos de las personas.

Evidentemente, el trabajo de desarrollar competencias interculturales, no debe realizarse únicamente con los que ingresan, sino que también es necesario un trabajo con los grupos que reciben a estas personas, es en este punto donde la perspectiva comunitaria toma también relevancia.

Para tomar otro ejemplo, en su trabajo con comunidades refugiadas en el contexto africano, Tete (2011), recuerda que ACNUR, provee tres soluciones a largo plazo para la situación de refugio que son la repatriación voluntaria al país de origen, la integración en el país de asilo o el reasentamiento en un tercer país de asilo. En esta investigación Tete (2011), trabaja casos de refugiados de Liberia en Ghana, en donde el concepto de hogar se presenta como algo no estático ni dependiente del país de proveniencia, y muchos de los refugiados se reusaban por diferentes motivos a querer volver a su país de origen, a pesar de que no se sentían "en casa" en Ghana. Parte de estos problemas se presentaban por encontrarse en campos de refugio en Liberia y la falta de facilidades para mejorar sus condiciones (trabajo, hogar, educación).

Sin embargo, en este caso podemos ver en las tres posibles soluciones planteadas institucionalmente, implican para los refugiados el tener que volver a realizar un encuentro con comunidades que pueden tener características culturales diferentes, ya sea en el caso del regreso voluntario, donde se verían en la necesidad de regresar a un lugar que dejaron hace mucho tiempo y que será diferente al que dejaron, o en el reasentamiento, donde deberían viajar a un nuevo destino, y se verían enfrentados de igual manera con una nueva cultura. 
Se hace evidente que no solo para las situaciones de refugio al momento de la migración original las competencias interculturales pueden aportar a facilitar los procesos de integración, sino que también se convierten necesarias para el momento en el cual se vuelve posible (o en algunos casos necesario) dejar la condición de refugiado.

Una excepción a esta visión de la adaptación como asimilación del "otro" la plantean Dobles y Jiménez (En ACNUR, 2008a), quienes acertadamente nos recuerdan que "las personas inmigrantes y refugiadas presentan una oportunidad de mejorar el conocimiento de nuestra propia cultura y su presencia no debería ser vivida como amenaza, sino como oportunidad de enriquecernos con personas, formas de vida y prácticas culturales que desconocíamos." (p.78). Esta visión, expuesta en el segundo capítulo del libro de ACNUR "Construyendo Comunidades", apunta hacia una visión de la integración como medio de crecimiento para el que llega y el que recibe, sin embargo, esta es una posición minoritaria en el mismo libro, donde en su mayoría se maneja el concepto tradicional de adaptación.

Es entonces, donde el concepto de competencias culturales se vuelve relevante desde este enfoque, ya que son el medio para aspirar a lo que Dobles y Jiménez (En ACNUR, 2008a) nos señalaban. Un aspecto necesario para la posibilidad de desarrollar competencias interculturales, es la posibilidad de tener encuentros con otras personas o con otros grupos, que ayuden a hacer evidentes nuestras propias características culturales, ya que todos estos valores, costumbres, tradiciones y las formas de interacciones características, son cosas que damos por sentado, por lo que no nos cuestionamos en su presencia en nuestra vida cotidiana, y es solo cuando nos encontramos con otras formas de ver $\mathrm{y}$ entender el mundo, que podemos poner todo lo que hemos aprendido en perspectiva, no como una verdad absoluta, sino únicamente como una de las tantas formas posibles de ver, hacer y entender las cosas.

He querido enfatizar a lo largo de este ensayo, que el incluir las competencias interculturales como eje transversal, de las intervenciones comunitarias con poblaciones refugiadas y las comunidades receptoras, si bien plantea un reto de trabajo y forma de hacer las cosas, tiene el potencial de generar verdaderos procesos de integración que beneficiarían no solo a las poblaciones refugiadas, sino también a todos aquellos costarricenses que interactúen en su vida cotidiana con ellos.

Como cierre se retoma lo que menciona Jiménez (2009), quien recuerda que "la migración no es una circunstancia pasajera ni un hecho menor de la historia del país. Es un dato estructural que marca la vida económica, política, social y cultural de este país. (p. 16), este mismo autor continua señalando, muy acertadamente, que "Costa Rica necesita reconocer y enfrentar tendencias institucionales que no contribuyen a la integración de las poblaciones inmigrantes y refugiadas" (Jiménez, 2009, p. 136), y es en este ámbito donde el trabajo de desarrollo de competencias 
interculturales presenta su mayor potencial, ya que siendo un país receptor (y expulsor) de migrantes, contamos con el potencial de diversidad necesario para el trabajo en formación de competencias interculturales, que permitan la búsqueda de una sociedad consciente de sus propias fortalezas y limitaciones, y de esa forma "ampliar sus horizontes y enriquecer sus recursos intelectuales $y$ espirituales, aprendiendo de visiones alternativas de la epistemología, la ética, la estética, y las visiones del mundo" (UNESCO, 2013, p.4).

\section{Notas}

1 Mencionar las perspectivas y aportes de cada uno de estos trabajos supera los alcances del presente ensayo, sin embargo se consideró importante mencionarlos como referencia para quien quiera trabajar el tema de refugiados colombianos en Costa Rica.

2 Se refiere a los diálogos que se producen entre los miembros de diferentes grupos culturales. El diálogo intercultural presupone que los participantes están de acuerdo en escuchar y comprender múltiples perspectivas, incluyendo incluso las realizadas por grupos o individuos con los que no están de acuerdo. (UNESCO, 2013, p. 14)

Vale aclarar que Smith (2008) utiliza el término americano, para referirse a la cultura estadounidense.

\section{Referencias Bibliográficas}

Alto Comisionado de las Naciones Unidas para los Refugiados (2008a). Construyendo una comunidad: la integración de niños, niñas y adolescentes refugiados colombianos en Costa Rica. San José, Costa Rica: ACNUR.

Alto Comisionado de las Naciones Unidas para los Refugiados (2008b). Enfoque Comunitario en las operaciones del ACNUR. [Versión Digital] Tomado de: http://www.acnur.org/paginas/index.php?id_pag=7775

Alto Comisionado de las Naciones Unidas para los Refugiados (2011). EL ACNUR en Costa Rica 2011. [Versión Digital] Tomado de: http://www.acnur.org/ $\mathrm{t} 3 /$ fileadmin/scripts/doc.php?file=t3/uploads/tx_refugiadosamericas/El_ ACNUR_en_Costa_Rica_2011

Alto Comisionado de las Naciones Unidas para los Refugiados. (2013, Junio 17). Costa rica: ACNUR busca visibilizar rostros de familias que huyen de la persecución. Tomado de: http://www.acnur.org/t3/noticias/noticia/costa-ricaacnur-busca-visibilizar-rostros-de-familias-que-huyen-de-la-persecucion/

Alto Comisionado de las Naciones Unidas para los Refugiados. (2014, Junio 20). Empresas en Costa Rica son reconocidas por buenas prácticas de integración 
de personas refugiadas. Tomado de: http://www.acnur.org/t3/noticias/ noticia/empresas-en-costa-rica-son-reconocidas-por-buenas-practicas-deintegracion-de-personas-refugiadas/

Chávez Soto, M. (2006). Refugiados colombianos en Costa Rica: atendidos por la Asociación de Consultores y Asesores Internacionales (ACAI). (Tesis de Licenciatura) Universidad de Costa Rica. San José, Costa Rica.

Duque Echeverri, V. (2009). Fortalecimiento del proceso de adaptación de niños y niñas colombianos refugiados por medio de la terapia de juego. (Memoria de Licenciatura) Universidad de Costa Rica. San José, Costa Rica.

Duneque, M. (2011) L'asile au Costa Rica = El asilo en Costa Rica. (Tesis de Licenciatura) Universidad de Costa Rica. San José, Costa Rica.

Jiménez, A. (2009) La vida en otra parte. Migraciones y cambios culturales en Costa Rica. San José: Editorial Arlekín.

Gonzáles Villalobos, R.; Hernández Vindas, M. (2005). Las agencias implementadoras de Programas del ACNUR orientadas a las soluciones duraderas de integración a nivel local: análisis del ACAI en Costa Rica (Tesis de Licenciatura) Universidad de Costa Rica. San José, Costa Rica.

Gutiérrez Bonilla, L.; Valverde López, M. (2011). Evaluación del Programa de Microcrédito implementado por ACNUR, ACAI y APRODE, en función de sus aportes a la integración local económica de la población colombiana refugiada en Costa Rica: estudio de casos de proyectos exitosos y no exitosos en zonas rurales y urbanas; 2002-2010. (Tesis de Licenciatura) Universidad de Costa Rica. San José, Costa Rica.

Medina Amador, J. M. (2006). Efectos del conflicto armado colombiano en la vigencia de los derechos humanos y sus repercusiones en el flujo migratorio hacia Costa Rica. (Tesis de Licenciatura) Universidad de Costa Rica. San José, Costa Rica.

Morales Morera, A.; Vargas Selva, G. (2008) La expresión del eje continuidadruptura en la identidad del (a) refugiado (a) colombiano (a) en Costa Rica. (Trabajo Final de Graduación, Escuela de Psicología: Universidad de Costa Rica.)

Salas Matamoros, A. (2014). Una ida, una llegada: la inserción social de los jóvenes colombianos refugiados en Costa Rica. (Tesis de Licenciatura) Universidad de Costa Rica. San José, Costa Rica.

Smith, R. S. (2008). The case of a city where 1 in 6 residents is a refugee: Ecological factors and host community adaptation in successful 
resettlement. American Journal of Community Psychology, 42, 328-342. doi: 10.1007/s10464-008-9208-6

Tete, S.Y.A, (2011) Any place could be home: Embedding refugees voices into displacement resolution and state refugee policy. Geoforum, 43, 106-115. doi: 10.1016/j.geoforum.2011.07.009

Ugalde Watson, K. (2009). Predictores de estrés por aculturación: el rol de la percepción de la discriminación, la salud y las redes de apoyo en personas adultas refugiadas colombianas en Costa Rica. (Tesis de Licenciatura) Universidad de Costa Rica. San José, Costa Rica.

United Nations Educational, Scientific and Cultural Organization (2013) Intercultural Competences: Conceptual and Operational Framework. [Versión Digital] Tomado de: http://unesdoc.unesco.org/images/0021/002197/219768e.pdf

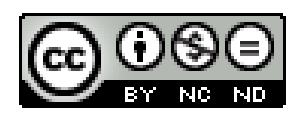

Este obra está bajo una licencia de Creative Commons ReconocimientoNoComercial-SinObraDerivada 4.0 Internacional. 